\title{
LETTERS
}

\section{Grosso's Review of Ring's Heading Toward Omega}

To the Editor:

I wish to thank Michael Grosso for his excellent review of Kenneth Ring's book Heading Toward Omega (Grosso, 1985). Grosso's additional comments referring to "the new literature of hope" and "what might be called the evolutionary imperative" address a theme that has been close to my heart since my near-death experience.

As one of the subjects in Ring's book, I would like to elaborate on a few issues. In noting that the interview excerpts in Heading Toward Omega leave Ring open to charges that his findings are due to an experimenter effect, Grosso cited the following interchange between Ring and myself as an example that "could be construed as a perfect illustration of experimenter effect"? (1985, p. 51)

the interviewer (presumably Ring) says: "And you really dic experience the real you in this state, it seems." And the interviewee responds: "Yeah, I knew at that point that I had met myself.'

It might appear from that excerpt from Heading Toward Omega (Ring, 1984, p. 107) that Ring was putting words into my mouth that is a danger in any interview. In my case, however, that was not true. That interview, done over two days, contained four and a half hours of tape. I had come to Connecticut to meet Ring with those ideas expressed throughout his book very set in my mind During the taping, which followed four days of talks, Ring may have moved me along from topic to topic, but the ideas expressed were all originally my own.

Now that I am also working as a near-death researcher at the University of Connecticut, I realize that those ideas I once thought so personally mine might be expressed by anyone who has had a core experience, triggered either near death or in any other way I also realize how strong minded "core experiencers" are as a group Far from our opinions in Ring's book being a result of ar experimenter effect, they have come from us, and even feel as though they have come through us from a higher source. 
